Article

\title{
Integrating CAD and 3D-Printing Techniques to Construct an In Vitro Laser Standard Treatment Platform for Evaluating the Effectiveness of Sterilization by Er:YAG Laser in Peri-Implant Intra-Bony Defects ${ }^{+}$
}

\author{
Shih-Hao Chang ${ }^{1,2}{ }^{\mathbb{D}}$, Hsiang-I Mei ${ }^{3}$ and Chun-Li Lin ${ }^{3, *(\mathbb{D}}$ \\ 1 Department of Periodontology, Chang Gung Memorial Hospital, Taoyuan 333, Taiwan; \\ sebastianshchang@gmail.com \\ 2 Graduate Institute of Dental and Craniofacial Science, Chang Gung University, No.259, Wen-Hwa 1st Road, \\ Kwei-Shan, Taoyuan 333, Taiwan \\ 3 Department of Biomedical Engineering, National Yang-Ming University, No.155, Sec. 2, Linong Street, \\ Taipei 112, Taiwan; angel09332002@gmail.com \\ * Correspondence: cllin2@ym.edu.tw \\ + Constructing a laser standard treatment platform for evaluating implant surface sterilization.
}

Received: 12 April 2020; Accepted: 13 May 2020; Published: 15 May 2020

\begin{abstract}
This study established an in vitro model mimicking clinical peri-implant intra-bony defects. We investigated the effect of access limitation and the bactericidal effectiveness of erbium-doped yttrium, aluminum and garnet (Er:YAG) laser irradiation in shallow and deep peri-implant defects at different tooth positions. Reverse engineering, computer-aided design (CAD), and 3D-printing techniques were integrated to establish physical peri-implant intra-bony defect models at mandibular central incisor, first premolar, and first molar positions with shallow ( $2 \mathrm{~mm}$ depth) or deep (6 $\mathrm{mm}$ depth) defects and with $1.5 \mathrm{~mm}$ and $1.8 \mathrm{~mm}$ widths at the bottom and crestal portions of the alveolar process, respectively. Three-dimensional printed suites at the corresponding implant sites replaced experimental implant specimens for the investigation of bacterial adhesion in individuals. Dental implants with diameters of 3,4 and $5 \mathrm{~mm}$ were utilized at the mandibular incisor, premolar, and molar positions, respectively. Bacterial adhesion of Gram (-) Escherichia coli on the exposed implant surfaces prior to sterilization was assessed. Sterilization with shallow and deep intra-bony defects was investigated by measuring the reduction of residual viable bacteria on implants after $60 \mathrm{~s}$ of irradiation with an Er:YAG laser. The adhesion rate of Gram (-) Escherichia coli on the investigated implant surfaces ranged from $1 \%$ to $3 \%(1.76 \pm 1.25 \%, 2.19 \pm 0.75 \%$ and $2.66 \pm 1.26 \%$ for 3,4 , and $5 \mathrm{~mm}$ implants, respectively). With shallow peri-implant bony defects, the Er:YAG laser sterilization rates were $99.6 \pm 0.5 \%, 99.3 \pm 0.41 \%$ and $93.8 \pm 7.65 \%$ at mandibular incisor, premolar, and molar positions, respectively. Similarly, sterilization rates in deep peri-implant defects were $99 \pm 1.35 \%, 99.1 \pm 0.98 \%$ and $97.14 \pm 2.57 \%$, respectively. A 3D-printed model with replaceable implant specimens mimicking human peri-implant intra-bony defects was established and tested in vitro. This investigation demonstrated effective sterilization using Er:YAG laser irradiation in both shallow and deep peri-implant intra-bony defects at different positions and diameters of dental implants.
\end{abstract}

Keywords: 3D printing model; peri-implantitis; intra-bony defect; Er:YAG laser; bactericide 


\section{Introduction}

Dental implant therapy has had a high success rate with successful maintenance for many years. Nevertheless, peri-implant inflammation is commonly observed after placing dental implants [1]. Peri-implant diseases have become increasingly relevant with the growing role of implant therapy in modern dentistry. Peri-implant diseases comprise two entities: peri-implant mucositis and peri-implantitis [2]. Peri-implant mucositis describes an inflammatory lesion residing in the soft tissues, while peri-implantitis describes an inflammatory reaction involving both the soft tissues and the supporting bone around the implant [3,4]. A recent systematic review and meta-analysis focused on the prevalence of peri-implant diseases in 47 selected studies with at least a three-year average follow-up period and at least 30 subjects and implants [5]. Therein, Lee et al. reported weighted mean prevalence of implant- and subject-based peri-implantitis and peri-implant mucositis of $9.25 \%, 19.83 \%$, $29.48 \%$ and $46.83 \%$, respectively.

Removal of bacterial deposits is essential in the treatment of peri-implant infections. Various therapeutic modalities, including chemical and mechanical disruption of peri-implant biofilm, have been shown to have certain beneficial effects on peri-implant infections [6]. However, biofilm-associated infection may be resistant to antimicrobial therapy without mechanical disruption [6]. The overall resistance of biofilm bacteria may be attributed to protection by extracellular polymeric substances, the adoption of resistant physiological states or phenotypes, or the horizontal transfer of resistance and virulence genes within the biofilm community [7-9]. Non-surgical mechanical treatment was found to be ineffective for peri-implantitis in various clinical trials and reviews [10-12]. Hence, surgical and regenerative therapies are preferred for the management of peri-implantitis lesions [13]. Many implant surface decontamination methods using chemical agents, mechanical debridement, or lasers have been proposed. Several methods or agents, including saline, citric acid, chlorhexidine, air-powder abrasion, hydrogen peroxide, and antimicrobials, have been used for surface decontamination in the surgical management of peri-implantitis lesions, but no agent has been found to be superior $[13,14]$. The use of mechanical instruments such as metal curettes and ultrasonic scalers on titanium is prohibited as it may cause significant implant surface alterations that may lead to plaque attachment $[15,16]$. Subsequently, the application of lasers has been considered for decontamination of implant surfaces.

The wavelengths of lasers most commonly used in periodontics, including diode lasers, neodymium-doped yttrium, aluminum and garnet (Nd:YAG) lasers, erbium-doped yttrium, aluminum and garnet (Er:YAG) lasers and $\mathrm{CO}_{2}$ lasers range from 819 to $10,600 \mathrm{~nm}$. Of the lasers emitting in the near- and mid-infrared spectral range, the Er:YAG laser exhibits high absorption of its emission wavelength $(2940 \mathrm{~nm})$ in water and provides the capability to remove calculus effectively without causing thermal side effects to the adjacent tissues [16]. The interaction between laser light and metal surfaces is mainly determined by the degree of absorption and reflection. Each metal features a certain spectral reflection capacity that is dependent upon the specific wavelength of the laser. The reflection capacity of titanium for an Er:YAG laser with a $2940 \mathrm{~nm}$ wavelength is $71 \%$, whereas the reflection capacity of titanium for a $\mathrm{CO}_{2}$ laser at $10,000 \mathrm{~nm}$ is $96 \%$ [17]. With high reflectivity, the implant surface does not absorb the radiation, and subsequently, there is no temperature increase, which could damage the implant surface. An in vitro study showed a bactericidal effect and no excessive temperature elevation with Er:YAG laser irradiation of different titanium surfaces [18]. Another in vitro study showed that Er:YAG, $\mathrm{CO}_{2}$ and diode lasers could achieve a high percentage or complete elimination of surface bacteria on contaminated titanium surfaces [19]. Other investigations showed that $\mathrm{CO}_{2}$ and diode lasers did not cause surface alterations following irradiation [20,21]. Conversely, Nd:YAG laser irradiation caused extensive surface melting of titanium discs irrespective of output energy [22]. Studies investigating temperature changes of implant surfaces after laser irradiation showed that diode lasers caused a temperature increase above the critical threshold of 10 ${ }^{\circ} \mathrm{C}$ after only $10 \mathrm{~s}$ and was ineffective at removing calcified deposits [16,23]. Conversely, use of the 
Er:YAG laser irradiation for implant treatment was demonstrated without altering the titanium surface if proper settings were applied [20,21].

Nevertheless, complete implant surface decontamination using chemical and mechanical procedures has been proven unsuccessful for the following reasons: (1) limited access to implant microstructures, (2) the presence of resistant bacterial strains, (3) ineffective drug dosages and (4) inadequate bactericidal effect [24]. Several other factors, including the equipment utilized, the macroand micro-texture of the implant and local anatomy and access, may influence the effectiveness of surface decontamination of biofilm-contaminated implants. In addition, biofilms adhere more strongly to rough implant surfaces than to smooth ones [25]. Previous in vitro investigations mostly applied laser irradiation to titanium discs with smooth or rough surfaces. These studies were not able to evaluate the effects of anatomical access limitations caused by peri-implant intra-bony defects and macro-structures of implants on the effectiveness of implant surface decontamination in clinical scenarios. Therefore, the aims of the present study were to integrate computer-aided design (CAD), reverse engineering and 3D-printing techniques to establish an experimental model mimicking various peri-implant intra-bony defects of root-form implants with rough surface texture between teeth. We evaluated the influence of access limitation and the effectiveness of biofilm decontamination by an Er:YAG laser in these clinically relevant models. Herein, we demonstrate effective sterilization using Er:YAG laser irradiation in both shallow and deep peri-implant intra-bony defects at different positions and diameters of dental implants.

\section{Materials and Methods}

To evaluate the effects of access limitation with different peri-implant intra-bony defects on the implant surface sterilization effectiveness of Er:YAG lasers, six groups with shallow or deep peri-implant intra-bony defects surrounding textured-surface dental implants were placed in three positions (mandibular central incisor, first premolar, and first molar). These models mimic clinical peri-implant situations. Five specimens in each group were tested for bacterial adhesion and laser sterilization. All bacterial culture, adhesion and laser sterilization tests were performed using standard operational cabinets in a P1 level laboratory in the Department of Biomedical Engineering, National Yang-Ming University, Taipei, Taiwan.

\subsection{Three-Dimensional Peri-Implantitis Model Generation}

To simulate the anatomical environments and real relationships between dental implants and adjacent tissues in humans, 3D digital models of dental implants $(3 \mathrm{~mm}, 4 \mathrm{~mm}$ and $5 \mathrm{~mm}$ diameters; $11.5 \mathrm{~mm}$ length) with sandblasted large-grit acid-etched surfaces (Anker SB, Alliance Global Technology Co., LTD. Kaoshiung, Taiwan) were generated. A plastic human adult standard dento-alveolar model (PRO2001-UL-SP-FEM-28, Nissin Dental Product Inc., Kyoto, Japan) was used for reverse engineering and CAD techniques according to our previous study [26] (Figure 1a). Three dental implants with $3 \mathrm{~mm}$, $4 \mathrm{~mm}$, and $5 \mathrm{~mm}$ diameters were placed at the left mandibular central incisor, first premolar, and first molar positions in the human dento-alveolar model, respectively. Shallow and deep peri-implant intra-bony defects with $2 \mathrm{~mm}$ or $6 \mathrm{~mm}$ depths, respectively, were then created with $1.8 \mathrm{~mm}$ crestal width and $1.5 \mathrm{~mm}$ apical width around the implants (Figure $1 \mathrm{~b}$ and Table 1). Experimental models constructed with acrylonitrile butadiene styrene (ABS) (ABS-P430, Stratasys, Ltd., Eden Prairie, Minnesota, USA) with peri-implant defects at mandibular incisor, premolar, and molar positions were printed using a 3D printer (Dimension 1200es SST, Stratasys Inc., Eden Prairie, Minnesota, USA) (Figure 1c). Six groups (three implant positions and two types of intra-bony defect) with five specimens per group were used in the experiments. 

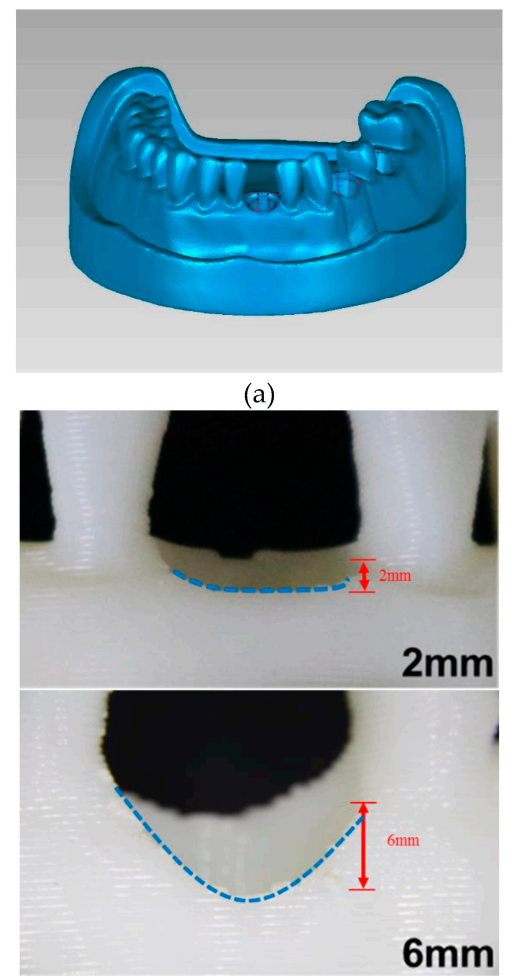

(b)

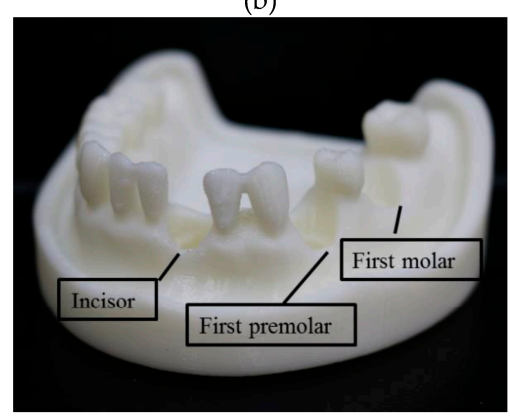

(c)

Figure 1. Peri-implantitis model design. (a) Computer-aided design (CAD) model of peri-implantitis scanned from a digital jaw model. (b) Shallow and deep peri-implant intra-bony defects designed with $2 \mathrm{~mm}$ and $6 \mathrm{~mm}$ depth. (c) Acrylonitrile butadiene styrene (ABS) 3D-printed model with peri-implantitis at mandibular incisor, premolar, and molar positions.

Table 1. Design of two types of modeling of peri-implantitis with alveolar bone resorption.

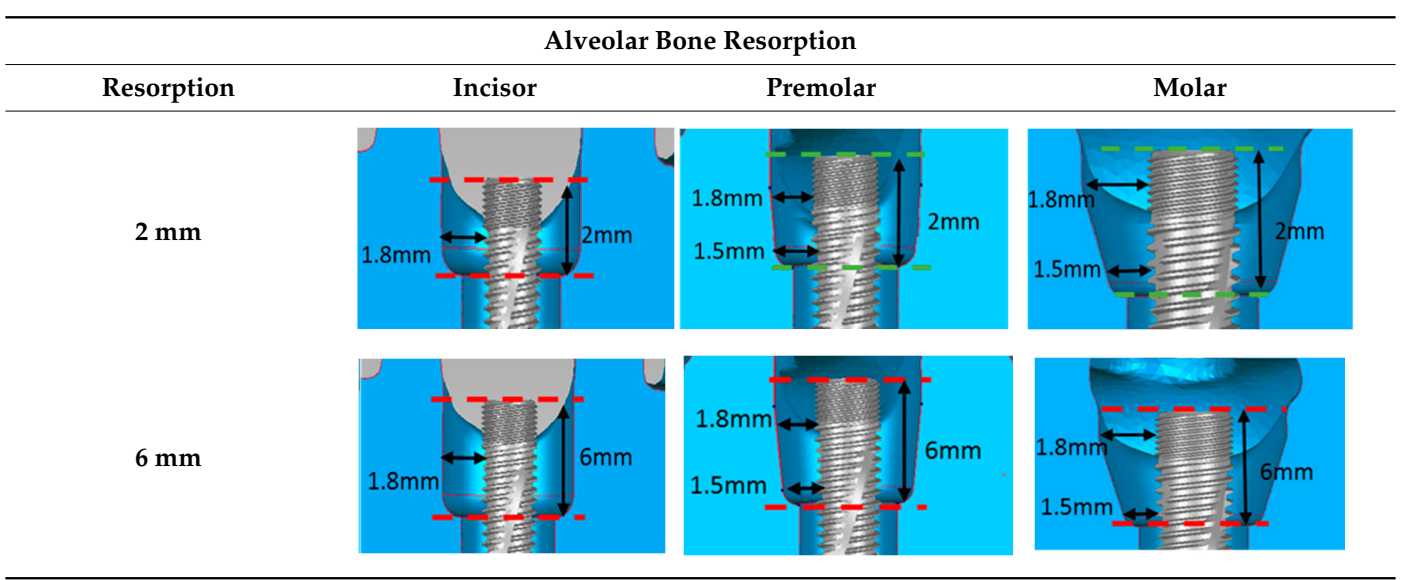


Three types of cylindrical suites $7.5 \mathrm{~mm}$ in height, 5, 6, or 7-mm in diameter and $1.5 \mathrm{~mm}$ in thickness with a $2 \mathrm{~mm}$-wide side key for connection to respective dental implants at the positions of mandibular incisor, premolar, and molar were designed. This permitted the suite to be replaced for individual bacterial adhesion experiments. The dental implant and suite comprised one experimental unit with which bacterial culture experiments were performed (Figure 2). The shallow $(2 \mathrm{~mm})$ and deep $(6 \mathrm{~mm})$ peri-implant intra-bony defect digital models and suite models were printed by 3D printer and transferred to ABS dento-alveolar models (Figure 1b,c and Figure 2b,c).

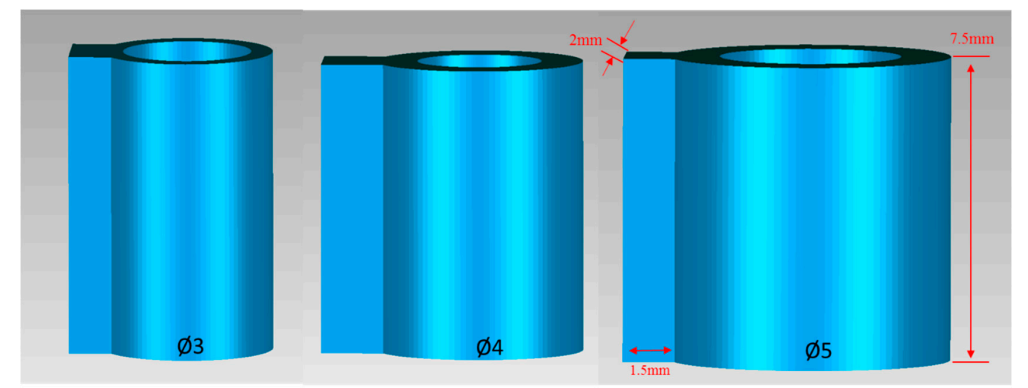

(a)

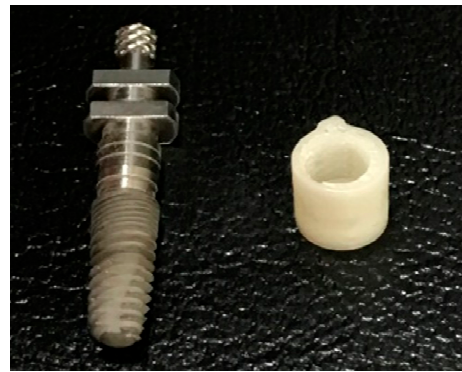

(b)

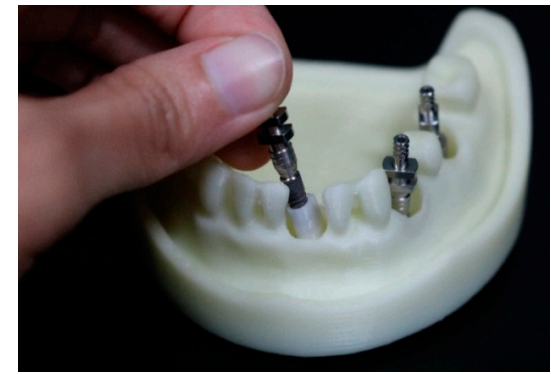

(c)

Figure 2. (a) Three-dimensional (3D) CAD model of suites for incisor, first premolar, and first molar positions. (b) One implant with mapping suite set. (c) Transfer of the implant and mapping suite set to the ABS peri-implantitis model.

\subsection{Bacterial Culture and Adhesion on Implants}

In a standard operation cabinet, suspensions of Gram-negative Escherichia coli (ATCC ${ }^{\circledR} 25922^{\mathrm{TM}}$ KWIK-STIK, Microbiologics Inc., St. Cloud, Minnesota, USA) in sterile saline solution were prepared by adjusting the turbidity to an optical density (OD) equivalent to a concentration of $10^{7}$ colony forming units (CFUs)/mL using a spectrophotometer at a $600 \mathrm{~nm}$ wave length (DU800, Beckman Coulter, Fullerton, CA, USA).

Five specimens (implants with $6 \mathrm{~mm}$ bone defects and corresponding suites) in each implant group representing the mandibular incisor, premolar, and molar positions were incubated with bacterial suspension solutions at $37^{\circ} \mathrm{C}$ for $24 \mathrm{~h}$. Two milliliters of medium were added to centrifuge tubes. The OD of the suspension diluted 10:1 was measured using a spectrophotometer. Plate counts were performed after 5 min of shaking using an ultra-sonicator (Elmasonic P, Elma Group Inc., Pforzheim, Germany) with a frequency $37 \mathrm{kHz}$ at $21^{\circ} \mathrm{C}$. The adhesion rates were calculated using the following formula:

$$
N_{a r}=\left[\frac{N_{a 1}}{N_{a 0}}\right] \times 100 \%
$$

( $N_{a r}=$ bacterial adhesion rate (percentage), $N_{a 1}=$ bacterial adhesion to the implant, $N_{a 0}=$ number of bacteria in the original bacterial solution). 


\subsection{Erbium-Doped Yttrium, Aluminum and Garnet (Er:YAG) Laser Sterilization of Contaminated Implants}

Specimens were assembled into 3D human dento-alveolar models and attached to a simulation manikin (KaVo EWL Dental Simulation Unit Phantom Head, KaVo Dental GmbH, Biberach, Germany) for laser sterilization experiments (Figure 3). The laser sterilization tests were performed with shallow $(2 \mathrm{~mm})$ or deep $(6 \mathrm{~mm})$ peri-implant intra-bony defects around textured-surface dental implants placed in three positions (mandibular central incisor, first premolar, and first molar) using 5 specimens per group. Each implant specimen contaminated with bacteria was irradiated with an Er:YAG laser (Er:YAG laser, LightMed Dental Technology Corp., Taiwan) at $100 \mathrm{~mJ} / 10 \mathrm{~Hz}$ and 2c.c./min water irrigation in non-contact pulse mode with a chisel-shaped sapphire tip $(0.6 \times 1.7 \mathrm{~mm}$ diameter at the tip) for $60 \mathrm{~s}$ (Figure 3). The application tip was moved across the buccal surface of the implant thread to the lingual and apical surfaces and finally to the root.

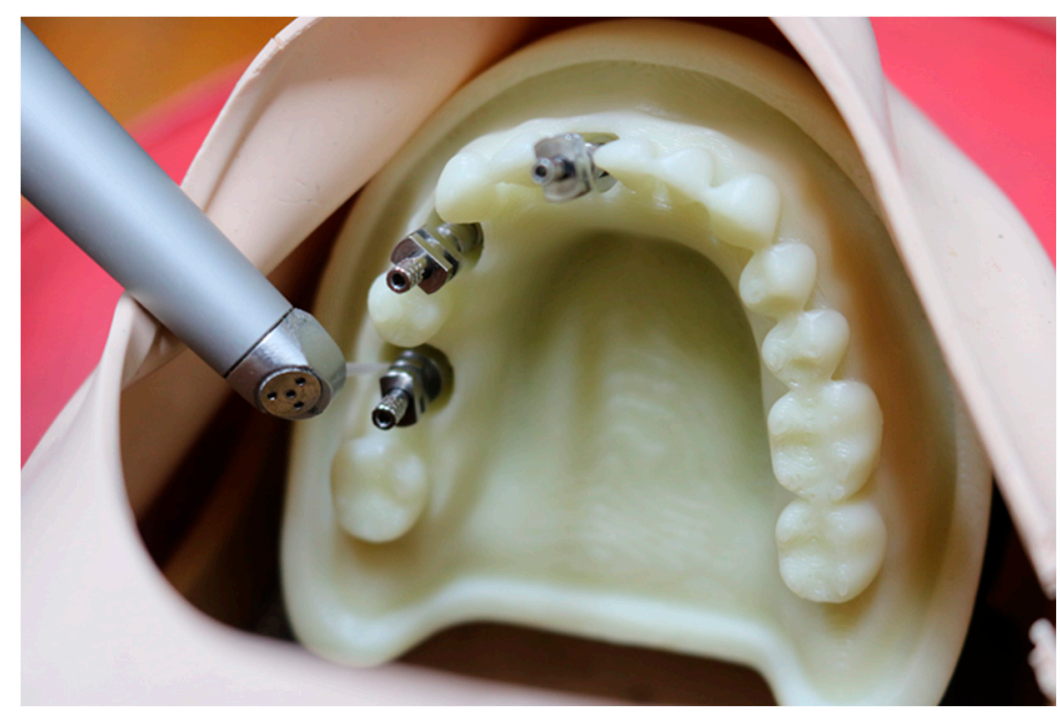

Figure 3. Illustration of laser treatment of the in vitro peri-implantitis model.

The abutment of the implant was placed into a centrifuge tube for bacteria count. Bacteria were counted by plate count after $5 \mathrm{~min}$ of shaking using an ultra-sonicator as described above. T-tests were used to evaluate statistical differences between implant positions and bone defect depths.

The Er:YAG dental laser sterilization rate was calculated using the following formula:

$$
N_{s r}=\left[\frac{N_{s 0}-N_{s 1}}{N_{s 0}}\right] \times 100 \%
$$

( $N_{s r}=$ sterilization rate, $N_{s 1}=$ bacterial adhesion to the implant after irradiation, $N_{s 0}=$ number of bacteria in the original bacterial solution).

\section{Results}

To assess the effects of access limitation in the context of peri-implant intra-bony defects and local anatomical structures, a 3D-printed human dento-alveolar model with substitutable implant unit sets (implant and suite) representing shallow or deep peri-implant intra-bony defects was designed by integrating reverse engineering, $\mathrm{CAD}$, and $3 \mathrm{D}$ printing techniques. The fabricated peri-implant intra-bony defect ABS model can also be attached to a simulation manikin to mimic clinical treatment scenarios (Figures 1-3).

The rate of adhesion of Gram-negative Escherichia coli to the investigated implant surfaces ranged from $1 \%$ to $3 \%(1.76 \pm 1.25 \%$ on the $3 \mathrm{~mm}$ implant, $2.19 \pm 0.75 \%$ on the $4 \mathrm{~mm}$ implant and $2.66 \pm 1.26 \%$ on the $5 \mathrm{~mm}$ implant, respectively) (Table 2). The results of laser irradiation experiments showed 
that sterilization rates with shallow $(2 \mathrm{~mm})$ peri-implant bony defects were $99.6 \pm 0.5 \%, 99.3 \pm 0.41 \%$, $93.8 \pm 7.65 \%$ at mandibular incisor $(3 \mathrm{~mm})$, premolar $(4 \mathrm{~mm})$ and molar $(5 \mathrm{~mm})$ positions, respectively (Table 3). Similarly, the corresponding sterilization rates with deep $(6 \mathrm{~mm})$ intra-bony defects were $99 \pm 1.35 \%, 99.1 \pm 0.98 \%$ and $97.14 \pm 2.57 \%$, respectively (Table 3 ). However, no significant differences $(p>0.05)$ in sterilization rates were found between implant positions and bone defect depths.

Table 2. Bacterial adhesion on different sandblasted and acid-etched dental implants with deep (6 mm) intra-bony defects at different tooth positions.

\begin{tabular}{|c|c|c|c|}
\hline \multicolumn{4}{|c|}{ Bacterial Adhesion on Dental Implants } \\
\hline Position & Sample & Adhesion Rate (\%) & Mean \pm SD \\
\hline \multirow{5}{*}{ Incisor (3 mm) } & Sample 1 & 1.25 & \multirow{5}{*}{$1.76 \pm 1.25$} \\
\hline & Sample 2 & 3.85 & \\
\hline & Sample 3 & 1.01 & \\
\hline & Sample 4 & 0.74 & \\
\hline & Sample 5 & 1.97 & \\
\hline \multirow{5}{*}{ Premolar (4 mm) } & Sample 1 & 1.94 & \multirow{5}{*}{$2.19 \pm 0.75$} \\
\hline & Sample 2 & 1.56 & \\
\hline & Sample 3 & 3.3 & \\
\hline & Sample 4 & 1.54 & \\
\hline & Sample 5 & 2.58 & \\
\hline \multirow{5}{*}{ Molar (5 mm) } & Sample 1 & 1.78 & \multirow{5}{*}{$2.66 \pm 1.26$} \\
\hline & Sample 2 & 1.20 & \\
\hline & Sample 3 & 2.62 & \\
\hline & Sample 4 & 4.37 & \\
\hline & Sample 5 & 3.34 & \\
\hline
\end{tabular}

Table 3. Erbium-doped yttrium, aluminum and garnet (Er:YAG) laser sterilization results with different levels of alveolar resorption and positions.

\begin{tabular}{|c|c|c|c|c|c|c|c|}
\hline \multirow[b]{3}{*}{$\begin{array}{c}\text { Alveolar } \\
\text { Resorption }\end{array}$} & \multirow{3}{*}{ Position } & \multicolumn{4}{|c|}{ Er:YAG Laser Sterilization Results } & \multirow{2}{*}{\multicolumn{2}{|c|}{ Molar (5 mm) }} \\
\hline & & \multicolumn{2}{|c|}{ Incisor (3 mm) } & \multicolumn{2}{|c|}{ Premolar $(4 \mathrm{~mm})$} & & \\
\hline & & $\begin{array}{c}\text { Sterilization } \\
\text { Rate (\%) }\end{array}$ & Mean \pm SD & $\begin{array}{c}\text { Sterilization } \\
\text { Rate (\%) }\end{array}$ & Mean \pm SD & $\begin{array}{l}\text { Sterilization } \\
\text { Rate (\%) }\end{array}$ & Mean \pm SD \\
\hline \multirow{5}{*}{$2 \mathrm{~mm}$} & Sample1 & 99.9 & \multirow{5}{*}{$99.6 \pm 0.5$} & 99.4 & \multirow{5}{*}{$99.3 \pm 0.41$} & 80.8 & \multirow{5}{*}{$93.8 \pm 7.65$} \\
\hline & Sample2 & 99.9 & & 99.3 & & 99.7 & \\
\hline & Sample3 & 100 & & 98.6 & & 97.3 & \\
\hline & Sample4 & 98.9 & & 99.4 & & 93 & \\
\hline & Sample5 & 99.2 & & 99.7 & & 98 & \\
\hline \multirow{5}{*}{$6 \mathrm{~mm}$} & Sample1 & 99.1 & \multirow{5}{*}{$99 \pm 1.35$} & 99.6 & \multirow{5}{*}{$99.1 \pm 0.98$} & 99 & \multirow{5}{*}{$97.14 \pm 2.57$} \\
\hline & Sample2 & 99.7 & & 99.9 & & 99.4 & \\
\hline & Sample3 & 99.8 & & 99.3 & & 95.1 & \\
\hline & Sample4 & 99.6 & & 99.2 & & 98.5 & \\
\hline & Sample5 & 96.6 & & 97.4 & & 93.7 & \\
\hline
\end{tabular}

\section{Discussion}

This study established an in vitro model mimicking clinical peri-implant intra-bony defects. We investigated the effects of access limitation and the bactericidal effectiveness of Er:YAG laser irradiation in shallow and deep peri-implant defects at different tooth positions. Most previous in vitro studies investigating the effects of bacterial adhesion and the cleaning effects of different instruments have used titanium discs instead of root-form dental implants [19-22,27,28]. Other studies utilized root-form dental implants embedded in resin blocks [23]. The effects of implant surface topography and surrounding bony defects on the efficacy of cleaning contaminated implant surfaces cannot be accurately evaluated using these models. Utilizing designable, re-printable 3D models with replaceable suites, the present study showed effective sterilization using Er:YAG laser irradiation with both shallow and deep peri-implant intra-bony defects at different positions and diameters of dental implants.

The effectiveness of laser irradiation on contaminated implant surfaces in a peri-implant defect may be influenced not only by the bony defect configuration, but also by peri-implant tissues in clinical or in vivo studies. Authors of a systematic review regarding periodontal and peri-implant 
wound healing following laser therapy stated that non-surgical therapy may not be sufficient for the healing of peri-implantitis sites [29]. The authors also found that the erbium lasers are advantageous in peri-implant surgery because of their favorable bone healing potential. Renvert et al. reported that surgical therapy is a predictable method for treating peri-implantitis but laser treatment of the exposed implant surface during surgery was not shown to be beneficial [30]. Considering the limited information currently available and the wide heterogeneity of clinical studies, superiority of laser treatment over conventional treatment of peri-implantitis has not been conclusive, although surgical laser therapy of peri-implantitis is able to achieve clinical improvement [31]. Controversial data may be reported because of the inherent heterogeneity in clinical and in vivo studies, although these studies are critical for the evaluation of implant cleaning procedures. The effectiveness of laser irradiation on the implant surface in non-surgical therapy may be significantly influenced by peri-implant soft tissues. Effects of peri-implant bony defect configurations on surgical therapy after flap reflection are expected to be greater than those of peri-implant soft tissues. To investigate the effects of the peri-implant soft tissues on the effectiveness of laser irradiation in non-surgical treatment, the models currently described mimicked surgical treatment situations for peri-implantitis with shallow and deep intra-bony defects. By integrating CAD and 3D-printing techniques to construct a standard in vitro laser treatment platform, this study provides an integrated process to investigate the effects of access limitation and defect configurations on the effectiveness of cleansing contaminated implant surfaces.

The present study investigated the sterilization effect of Er:YAG laser irradiation in shallow and deep peri-implant intra-bony defects that simulate clinical situations. Er:YAG laser irradiation effectively sterilized implants with both shallow and deep peri-implant bony defects in these models at mandibular incisor, premolar, and molar positions. There was no significant difference of sterilization effects between shallow and deep intra-bony defects using Er:YAG laser irradiation. A slightly lower sterilization rate was observed with the wider implants in the mandibular posterior region; however, these results were not statistically significant. Few studies have investigated the influence of defect configurations on implant surface decontamination. Schwarz et al. investigated two surface debridement/decontamination methods with intra-bony (class Ib, Ic, Ie) and supra-bony (class II) defects in patients with peri-implantitis [32-34]. Although these studies failed to demonstrate a significant impact of the surface decontamination method [32,34], a potential impact of defect configuration on clinical outcome following combined surgical therapy for advanced peri-implantitis lesions was identified [33]. The results of this study coincided with literature indicating that the decontamination effects of Er:YAG lasers were similar in different peri-implant intra-bony defect configurations with a proper contact tip and parameter settings [32,34]. In the present study, shallow $(2 \mathrm{~mm})$ and deep $(6 \mathrm{~mm})$ peri-implant intra-bony defects were created with similar crestal apical widths of $1.8 \mathrm{~mm}$ and $1.5 \mathrm{~mm}$, respectively (Figure 1a, Table 1). Considering the similar macro- and micro-topography of the implant models and similar dimension of intra-bony defects, the differences in sterilization rates between the three types of implant specimens may have been related to differences in implant surface area, the position of implants in the dental arch or access limitation by local anatomic structures including the buccal cheek. Further investigations are necessary to evaluate the effects of implant positions in dental arches and adjacent dental/facial anatomic features.

Although the clinically beneficial effects of mechanical and chemical interventions to disrupt peri-implant biofilms demonstrate convincingly that microorganisms are involved in the disease process, there is no evidence for the existence of one or a limited number of specific pathogens causing peri-implantitis. Previous microbiological findings in an experimental peri-implantitis model mimicking natural disease progression supported the notion that large variation in microbial profiles makes interpretation of a correlation between disease progression and specific microbes difficult [35]. In the current study, Gram-negative Escherichia coli was used to investigate bacterial adhesion and effects of laser decontamination on titanium implant surfaces. Although the biofilm compositions on contaminated implant surfaces in peri-implant diseases are complex and dominated by Gram-negative 
anaerobes $[6,35,36]$, several in vitro studies utilized single species bacterial biofilms for the investigation of implant surface contamination $[18,19,22]$.

The adhesion rate of Gram-negative Escherichia coli on the investigated implant surfaces prior to Er:YAG irradiation ranged from $1 \%$ to $3 \%$ (Table 2). Although these percentages seem low, the number of adhering bacteria reached $10^{6} \mathrm{CFU} / \mathrm{mL}$, which was equivalent to that described in the literature $[27,28]$. Studying the effect of surface roughness of titanium implants on the adhesion and removal of bacterial contamination, Chen et al. found no significant difference in Escherichia coli bacterial adhesion among surfaces of varying roughness, except in $50 \mu \mathrm{m}$ and $250 \mu \mathrm{m} \mathrm{Al}_{2} \mathrm{O}_{3}$ sandblasting groups at $12 \mathrm{~h}$ of culture [27]. The cleaning modalities investigated did not induce significant surface alterations. However, Escherichia coli adhesion was significantly reduced by air-powder abrasion and Er:YAG laser debridement in comparison to plastic curettage. The authors concluded that laser debridement could be a useful cleaning method for peri-implantitis therapy. Another in vitro study investigated bacterial adhesion on smooth and rough titanium disc surfaces after treatment with four different instruments using single species Streptococcus sanguinis (American Type Culture Collection 10556) bacterial suspensions [28]. The authors found that smooth titanium surfaces were altered significantly by metal curettage, yet there were no significant rough surface alterations before and after treatment with Er:YAG laser irradiation, plastic curettage, metal curettage, or air-powder abrasion. The findings of the present study were in line with the literature, showing that significant effectiveness of sterilization by Er:YAG laser irradiation could be achieved on Escherichia coli-contaminated rough titanium implant surfaces.

In the present study, clinical situations were simulated by real implant fixture placement in a 3D-printed standard human adult dento-alveolar model attached to a simulation manikin. However, effects of saliva and blood could not be simulated under the present experimental conditions. Considering the limitations of this model, it was difficult to determine whether implant diameter or access limitation caused a non-significant lower sterilization rate in wider implants at the mandibular posterior region. We concluded that effective sterilization rates could be achieved with Er:YAG laser irradiation with a proper contact tip and parameter settings irrespective of the depth and configuration of peri-implant intra-bony defects. Further studies are necessary to investigate similar effects on biofilms or multiple-species bacterial cultures. The use of integrated CAD and 3D-printing techniques to construct an in vitro laser standard treatment platform with different intra-bony defect configurations is demonstrated herein. Furthermore, these models were reverse-engineered from real peri-implantitis cases to visualize and simulate treatment procedures prior to surgery.

Author Contributions: All authors have made substantial contributions to conception and design of the study. H.-I.M. and C.-L.L. Lin have been involved in data collection and data analysis. S.-H.C. and C.-L.L. have been involved in data interpretation, drafting the manuscript and revising it critically and have given final approval of the version to be published. All authors have read and agreed to the published version of the manuscript.

Funding: MOST project 108-2622-E-010 -001 -CC2 and 108-2622-B-010 -005, Taiwan.

Acknowledgments: This study is supported in part by BY-12-05-28-105 of the Southern Taiwan Science Park Bureau, Ministry of Science and Technology and MOST project 108-2622-E-010 -001 -CC2 and 108-2622-B-010 -005, Taiwan. The authors would like to thank Alliance Global Technology Co., LTD. Taiwan for providing the implants for experimentation.

Conflicts of Interest: The authors declare no conflict of interest.

\section{References}

1. Adell, R.; Lekholm, U.; Rockler, B.; Branemark, P.-I. A 15-year study of osseointegrated implants in the treatment of the edentulous jaw. Int. J. Oral Surg. 1981, 10, 387-416. [CrossRef]

2. Zitzmann, N.-U.; Berglundh, T. Definition and prevalence of peri-implant diseases. J. Clin. Periodontol. 2008, 35, 286-291. [CrossRef]

3. Albrektsson, T.; Isidor, F. Consensus report of session IV. In Proceedings of the 1st European Workshop on Periodontology; Lang, N.P., Karring, T., Eds.; Quintessence: Berlin, Germany, 1994. 
4. Lindhe, J.; Meyle, J. Group DoEWoP: Peri-implant diseases: Consensus report of the sixth European workshop on periodontology. J. Clin. Periodontol. 2008, 35, 282-285. [CrossRef] [PubMed]

5. Lee, C.-T.; Huang, Y.-W.; Zhu, L.; Weltman, R. Prevalences of peri-implantitis and peri-implant mucositis: Systematic review and meta-analysis. J. Dent. 2017, 62, 1-12. [CrossRef]

6. Mombelli, A.; Decaillet, F. The characteristics of biofilms in peri-implant disease. J. Clin. Periodontol. 2011, 38, $203-213$. [CrossRef] [PubMed]

7. Costerton, J.-W.; Montanaro, L.; Arciola, C.-R. Biofilm in implant infections: Its production and regulation. Int. J. Artif. Organs 2005, 28, 1062-1068. [CrossRef] [PubMed]

8. Marsh, P.-D. Dental plaque: Biological significance of a biofilm and community life-style. J. Clin. Periodontol. 2005, 32, 7-15. [CrossRef]

9. Davey, M.-E.; Costerton, J.-W. Molecular genetics analyses of biofilm formation in oral isolates. Periodontology 2000, 42, 13-26. [CrossRef]

10. Renvert, S.; Samuelsson, E.; Lindahl, C.; Persson, G.-R. Mechanical non-surgical treatment of peri-implantitis: A double-blind randomized longitudinal clinical study. I: Clinical results. J. Clin. Periodontol. 2009, 36, 604-609. [CrossRef]

11. Esposito, M.; Grusovin, M.-G.; Coulthard, P.; Worthington, H.-V. The efficacy of interventions to treat peri-implantitis: A Cochrane systematic review of randomised controlled clinical trials. Eur. J. Oral Implantol. 2008, 9, 111-125.

12. Faggion, C.-M., Jr.; Chambrone, L.; Gondim, V.; Schmitter, M.; Tu, Y.-K. Comparison of the effects of treatment of peri-implant infection in animal and human studies: Systematic review and meta-analysis. Clin. Oral Implants Res. 2010, 21, 137-147. [CrossRef] [PubMed]

13. Aljateeli, M.; Fu, J.-H.; Wang, H.-L. Managing peri-implant bone loss: Current understanding. Clin. Implant. Dent. Relat. Res. 2003, 14, e109-e118. [CrossRef] [PubMed]

14. Ntrouka, V.-I.; Slot, D.-E.; Louropoulou, A.; van der Weijden, F. The effect of chemotherapeutic agents on contaminated titanium surfaces: A systematic review. Clin. Oral Implants Res. 2011, 22, 681-690. [CrossRef] [PubMed]

15. Fox, S.-C.; Moriarty, J.-D.; Kusy, R.-P. The effects of scaling a titanium implant surface with metal and plastic instruments: An in vitro study. J. Periodontol. 1990, 61, 485-490. [CrossRef] [PubMed]

16. Aoki, A.; Sasaki, K.-M.; Watanabe, H.; Ishikawa, I. Lasers in nonsurgical periodontal therapy. Periodontology 2000, 36, 59-97. [CrossRef] [PubMed]

17. Sculean, A.; Schwarz, F.; Becker, J. Anti-infective therapy with an Er:YAG laser: Influence on peri-implant healing. Expert Rev. Med. Devices 2005, 2, 267-276. [CrossRef]

18. Kreisler, M.; Kohnen, W.; Marinello, C.; Gotz, H.; Duschner, H.; Jansen, B. Bactericidal effect of the Er:YAG laser on dental implant surfaces: An in vitro study. J. Periodontol. 2002, 73, 1292-1298. [CrossRef]

19. Tosun, E.; Tasar, F.; Strauss, R.; Kivanc, D.-G.; C, C.U. Comparative evaluation of antimicrobial effects of Er:YAG, diode, and CO(2) lasers on titanium discs: An experimental study. J. Oral Maxillofac. Surg. 2012, 70, 1064-1069. [CrossRef]

20. Stubinger, S.; Etter, C.; Miskiewicz, M.; Homann, F.; Saldamli, B.; Wieland, M.; Sader, R. Surface alterations of polished and sandblasted and acid-etched titanium implants after Er:YAG, carbon dioxide, and diode laser irradiation. Int. J. Oral Maxillofac. Implants 2010, 25, 104-111.

21. Park, J.-H.; Heo, S.-J.; Koak, J.-Y.; Kim, S.-K.; Han, C.-H.; Lee, J.H. Effects of laser irradiation on machined and anodized titanium disks. Int. J. Oral Maxillofac. Implants 2012, 27, 265-272.

22. Romanos, G.-E.; Everts, H.; Nentwig, G.-H. Effects of diode and Nd:YAG laser irradiation on titanium discs: A scanning electron microscope examination. J. Periodontol. 2000, 71, 810-815. [CrossRef] [PubMed]

23. Geminiani, A.; Caton, J.-G.; Romanos, G.-E. Temperature change during non-contact diode laser irradiation of implant surfaces. Lasers Med. Sci. 2012, 27, 339-342. [CrossRef] [PubMed]

24. Mailoa, J.; Lin, G.-H.; Chan, H.-L.; MacEachern, M.; Wang, H.-L. Clinical outcomes of using lasers for peri-implantitis surface detoxification: A systematic review and meta-analysis. J. Periodontol. 2014, 85, 1194-1202. [CrossRef]

25. Quirynen, M.; van der Mei, H.-C.; Bollen, C.-M.L.; Schotte, A.; Marechal, M.; Doornbusch, G.-I.; Naert, I.; Busscher, H.-J.; van Steenberghe, D. An in vivo study of the influence of the surface roughness of implants on the microbiology of supra- and subgingival plaque. J. Dent. Res. 1993, 72, 1304-1309. [CrossRef] 
26. Kuo, H.-N.; Mei, H.-I.; Liu, T.-K.; Liu, T.-Y.; Lo, L.-J.; Lin, C.-L. In vitro laser treatment platform construction with dental implant thread surface on bacterial adhesion for peri-Implantitis. BioMed. Res. Int. 2017, 7, 4732302. [CrossRef] [PubMed]

27. Chen, C.-J.; Ding, S.-J.; Chen, C.-C. Effects of Surface Conditions of Titanium Dental Implants on Bacterial Adhesion. Photomed. Laser Surg. 2016, 34, 379-388. [CrossRef] [PubMed]

28. Duarte, P.-M.; Reis, A.-F.; de Freitas, P.-M.; Ota-Tsuzuki, C. Bacterial adhesion on smooth and rough titanium surfaces after treatment with different instruments. J. Periodontol. 2009, 80, 1824-1832. [CrossRef]

29. Aoki, A.; Mizutani, K.; Schwarz, F.; Sculean, A.; Yukna, R.-A.; Takasaki, A.-A.; Romanos, G.-E.; Taniguchi, Y.; Sasaki, K.-M.; Zeredo, J.-L.; et al. Periodontal and peri-implant wound healing following laser therapy. Periodontology 2000, 68, 217-269. [CrossRef]

30. Renvert, S.; Polyzois, I.; Claffey, N. Surgical therapy for the control of peri-implantitis. Clin. Oral Implants Res. 2012, 23, 84-94. [CrossRef]

31. Kotsakis, G.-A.; Konstantinidis, I.; Karoussis, I.-K.; Ma, X.; Chu, H. Systematic review and meta-analysis of the effect of various laser wavelengths in the treatment of peri-implantitis. J. Periodontol. 2014, 85, 1203-1213. [CrossRef]

32. Schwarz, F.; Sahm, N.; Iglhaut, G.; Becker, J. Impact of the method of surface debridement and decontamination on the clinical outcome following combined surgical therapy of peri-implantitis: A randomized controlled clinical study. J. Clin. Periodontol. 2011, 38, 276-284. [CrossRef] [PubMed]

33. Schwarz, F.; John, G.; Mainusch, S.; Sahm, N.; Becker, J. Combined surgical therapy of peri-implantitis evaluating two methods of surface debridement and decontamination. A two-year clinical follow up report. J. Clin. Periodontol. 2012, 39, 789-797. [CrossRef] [PubMed]

34. Schwarz, F.; Hegewald, A.; John, G.; Sahm, N.; Becker, J. Four-year follow-up of combined surgical therapy of advanced peri-implantitis evaluating two methods of surface decontamination. J. Clin. Periodontol. 2013, 40, 962-967. [CrossRef] [PubMed]

35. Charalampakis, G.; Abrahamsson, I.; Carcuac, O.; Dahlen, G.; Berglundh, T. Microbiota in experimental periodontitis and peri-implantitis in dogs. Clin. Oral Implants Res. 2014, 25, 1094-1098. [CrossRef]

36. Schwarz, F.; Papanicolau, P.; Rothamel, D.; Beck, B.; Herten, M.; Becker, J. Influence of plaque biofilm removal on reestablishment of the biocompatibility of contaminated titanium surfaces. J. Biomed. Mater. Res. 2006, 77, 437-444. [CrossRef] [PubMed] 